\title{
EDUCAÇÃO PATRIMONIAL: AÇÕES EDUCATIVAS NOS ESPAÇOS DE EDUCAÇÃO NÃO-FORMAIS A PARTIR DO PATRIMÔNIO ARQUEOLÓGICO
}

Heritage education: Educational actions in spaces of non-formal education from archeological heritage

\author{
Vania Maria Barboza ${ }^{1}$
}

${ }^{1}$ Mestra em Educação; Especialista em Processos Interdisciplinares em Arqueologia; Especialista em Psicopedagogia; Graduada em História. E-mail: vania@uri.com.br

RESUMO: A educação patrimonial é um recurso metodológico que oportuniza que crianças e adultos tenham contato com bens e fenômenos culturais, possibilitando que realizem relações com o lugar, atribuindo-lhe significados e percebendo a importância de sua preservação por ser referência de identidade e memória. Este estudo denominado "Educação patrimonial: ações educativas nos espaços não-formais, a partir do patrimônio arqueológico", tem como objetivo geral discutir a educação patrimonial em um espaço de educação não-formal por meio de oficinas educação patrimonial de como instrumento para se trabalhar cultura, memória e cidadania. A proposta para a realização deste estudo foi desenvolvida por meio de uma pesquisa qualitativa, na modalidade de pesquisa-ação, aplicada em um grupo de crianças e adolescentes que participam de um programa que desenvolve atividades socioeducativas, no município de Erechim. Esta proposta de estudo apresenta relevância acadêmica, pois permitirá discutir a educação patrimonial em um espaço de educação não-formal como instrumento para a construção da cidadania, de memória e valorização da cultura. A relevância social da proposta de Educação Patrimonial, na educação não-formal se efetiva em forma de inclusão social, pois oportunizou trabalhar nas oficinas objetos culturais indígenas que, historicamente, têm sido marginalizados pela sociedade, demonstrando às crianças a importância da valorização e da preservação dos saberes e tradições desses 
povos, e principalmente a importância do respeito à diferença, seja ela étnica, cultural ou religiosa. Esse entendimento possibilita aos indivíduos verem-se como cidadãos e, assim, defenderem seus direitos como tais.

Palavras-chave: Cultura. Cidadania. Memória. Arqueologia.

ABSTRACT: Heritage education is a methodological resource that allows children and adults to have contact with cultural assets and cultural phenomena, enabling them to realize relationships with the place, assigning meaning to it and realizing the importance of its preservation as a reference of identity and memory. This study, called "Heritage Education: educational actions in spaces of non-formal education from the archaeological heritage", has as a general objective to discuss heritage education in a non-formal education space through heritage education workshops as a tool to work culture, memory and citizenship. The proposal for this study was developed by means of a qualitative research, in the form of an action research, applied to a group of children and teenagers who participate in a program that develops socio-educational activities in the municipality of Erechim. This study presents academic relevance, since it will allow discussing heritage education in a non-formal education space as an instrument for the construction of citizenship, memory and culture valorization. The social relevance of the Heritage Education proposal, in non-formal education is effective in the form of social inclusion, as it made it possible to work in the workshops with indigenous cultural objects, which historically, have been marginalized by society, demonstrating to children the importance of valuing and preserving knowledge and traditions of these peoples, and especially the importance of the respect for what is different, whether ethnic, cultural or religious. This understanding allows individuals to see themselves as citizens and thus defend their rights as such.

Keywords: Culture. Citizenship. Memory. Archeology.

\section{Introdução}

No Brasil, apesar das ações de preservação do patrimônio histórico serem recentes, em diversos momentos importantes na história do país encontramos a preocupação com o destino de bens que lembram fatos importantes ocorridos no passado.

Lemos (2013) destaca a iniciativa precursora do Conde de Galveias que, no ano de 1742, redigiu uma carta a Luís Pereira Freire de Andrade, governador de Pernambuco, lamentando a transformação do Palácio das Duas Torres, obra do Conde de Nassau, em quartel das tropas locais. O Conde de Galveias apontava a importância da manutenção da integridade dessa construção holandesa, tendo em vista seu valor histórico, uma vez que era um marco das ações lusitanas na restauração da capitania.

A preocupação do nobre português com os bens históricos não surtiu efeitos frente à ação degradadora do patrimônio nacional, visto que a história contada pelos vencedores sempre buscou anular o vestígio da cultura 
dos vencidos, que muitas vezes se resume em fragmentos resgatados por colecionadores ou algum intelectual.

Em nosso país, fontes riquíssimas da história dos povos têm sido destruídas ou foram perdidas frente às conquistas territoriais e à invasão cultural. A imposição da cultura do invasor, da sua língua e religião, demonstra a força avassaladora do grupo dominante que, ao impor sua cultura e tradições, rompe com a cultura e com a identidade do grupo dominado. Como exemplo, é possível citar em Le Goff (2010) o embate total entre o antigo e o moderno, entre os europeus e os índios da América como acontecimento com consequências drásticas, uma vez que os índios foram vencidos, conquistados, destruídos e assimilados, numa clara demonstração imperialista e colonialista.

Darcy Ribeiro (2004, p.35) explanou com muita propriedade e riqueza de detalhes, em "O povo brasileiro", que os povos aqui encontrados estavam estruturados em "tribos autônomas, autárquicas e não estratificadas em classes, o enxame de invasores era a presença local avançada de uma vasta e vetusta civilização urbana e classista", que impôs a língua, a religiosidade e a cultura invasora aos indígenas, num processo gradativo de assimilação cultural.

Esse processo, visto como civilizatório, fez com que os costumes, a língua e a religiosidade, que fazem parte do patrimônio cultural dos povos que aqui estavam, fossem profundamente impactados, contribuindo para que muitos conhecimentos e bens culturais brasileiros, obras de arte, fossem gradativamente perdidos ou evadidos do país.

Alguns intelectuais brasileiros, uma parte vinculada à Semana de Arte Moderna, de 1922, influenciados pelo nacionalismo nascente no período pós Primeira Guerra Mundial e diante da constatação de que tesouros nacionais estavam sendo perdidos, se posicionaram contra o abandono e destruição do patrimônio nacional, apontando a responsabilidade do Estado pela sua preservação. A resposta do Estado foi dada na Constituição Federal de 1934, em seu art. 10, parágrafo $3^{\circ}$, que diz que é competência da União e dos Estados "proteger as belezas naturais e os monumentos de valor histórico ou artístico, podendo impedir a evasão de obras de arte" (BRASIL, 1934).

A iniciativa da intelectualidade brasileira da época contribuiu para a formação de "novas concepções sobre patrimônio e sua preservação" (RAMOS, 2016, p.86), o que pode ser percebido na solicitação de Gustavo Capanema, Ministro da Educação do Governo de Getúlio Vargas, a Mário de Andrade para redação de um documento com vistas à criação de um serviço de proteção do patrimônio histórico e artístico nacional - SPHAN, órgão precursor do IPHAN, em 1936.

O SPHAN, criado pelo Decreto-lei $\mathrm{n}^{\circ} 25$, de 30 de novembro de 1937, em 1946 passa a se denominar Departamento do Patrimônio Histórico e Artístico Nacional (DPHAN) que, em 1970, se transforma em IPHAN; em 1979, o IPHAN se divide em SPHAN - órgão normativo - e Fundação Nacional Pró-memória (FNpM) - órgão executivo; em 1990 ocorre a extinção do SPHAN e da FNpM e criação do Instituto Brasileiro do Patrimônio Cultural (IBPC); até que em 06 de dezembro de 1994, pela Medida Provisória de n ${ }^{\circ} 752$, o IBPC e o Instituto Brasileiro de Arte e Cultura IBA, passam a denominar-se, respectivamente, Instituto do Patrimônio Histórico e Artístico Nacional (IPHAN) e Fundação de Artes - FUNARTE (IPHAN, 2014).

Com o Decreto Lei $n^{\circ} 25 / 1937$, gradativamente foi sendo criada uma legislação de proteção do patrimônio histórico e artístico nacional, que passou a regulamentar os bens culturais brasileiros, dentre elas destaca-se a Constituição Federal de 1988 que dedicou 
uma seção para tratar da cultura e em seu art. 216 previu a preservação do patrimônio cultural material e imaterial (BRASIL, 1988).

Ao institucionalizar a cultura, a Carta Constitucional assumiu um importante compromisso, o de reconhecer a cidadania cultural de todos os brasileiros, assim como seu direito à educação e à cultura. Além disto, ao admitir o patrimônio imaterial como parte do patrimônio cultural nacional fica reconhecida a diversidade cultural e as manifestações de natureza imaterial dos diferentes grupos que formam a sociedade brasileira.

O presente artigo traz uma parte das atividades desenvolvidas no trabalho de campo do Mestrado Profissional em Educação da Universidade Federal da Fronteira Sul, aplicada em forma de oficinas de educação patrimonial com crianças com idades entre 9 e 14 anos, que participam de um programa que desenvolve atividades socioeducativas no município de Erechim.

\section{Cultura, memória e cidadania: suas relações com a educação patrimonial}

Partindo-se da premissa de que a Educação Patrimonial é uma importante ferramenta metodológica que pode ser utilizada para o estudo do patrimônio cultural de um grupo, de uma comunidade ou sociedade, é indispensável estudar as relações existentes entre os conceitos de cultura, memória e cidadania, para que se possa entender o vínculo de pertença e apoderamento com relação aos bens culturais disponíveis nos diferentes espaços sociais e a participação cidadã.

\section{A cultura}

Chegar à definição do que é cultura não é uma tarefa simples, uma vez que é um termo amplo e complexo que envolve dife- rentes aspectos da vida dos grupos humanos. Existem diferentes conceitos de cultura na atualidade e, conforme apontam Marconi e Presotto (2001), pode-se chegar a mais de 160 definições deste termo.

Iniciaremos pela etimologia da palavra cultura, derivada do latim culturae, que significa "ação de tratar", "cultivar" ou "cultivar a mente e os conhecimentos". Culturae tem sua origem no termo latino colere, que quer dizer "cultivar as plantas" ou "ato de plantar e desenvolver atividades agrícolas" (HOUAISS, 2009).

A palavra germânica Kultur foi utilizada no final do século XVIII e no início do século XIX para simbolizar todos os aspectos espirituais de uma comunidade, assim como o termo francês Civilization, que se referia especialmente às práticas materiais de um povo (LARAIA, 2009). A associação da palavra cultura com civilização era habitualmente utilizada pelos príncipes da nobreza alemã, "preocupados demais em imitar as maneiras civilizadas da corte francesa" (CUCHE, 2002, p.25).

Destaca Cuche (2002) que o termo kultur evoluiu mais rapidamente que sua homóloga francesa Civilization, visto que para a intelectualidade burguesa alemã, a adoção de seu uso era uma forma de oposição à aristocracia da corte. Nesse sentido, para esses, kultur era o contrário de civilização, uma vez que "consistia naquilo que era especificamente alemão, naquilo que distinguia esse povo e essa nação das demais; [...] kultur residiria o gênio nacional de um povo, sua profundidade, sua espiritualidade" (COELHO, 2008, p.21). Assim, a cultura passa a ser entendida como uma marca característica da originalidade e superioridade do povo alemão, ideia que permeou as discussões nacionalistas alemãs nos períodos históricos posteriores, que culminariam na Primeira Guerra Mundial (CUCHE, 2002). 
A rivalidade nacionalista francesa e alemã e seu embate violento na Primeira Guerra Mundial acentuam o debate ideológico entre as duas concepções de cultura. Segundo Cuche (2002, p.30) "As palavras tornam-se slogans utilizados como armas". De um lado a concepção particularista alemã e de outro a universalista, francesa.

Apesar do uso das variantes Civilization e Kultur, desde o século XVIII, Oliveira e Alves (2005) lembram que foi Edward Burnett Tylor, em 1877, quem empregou pela primeira vez o vocábulo inglês culture, em amplo sentido, se referindo a todos os costumes, hábitos, aptidões, os produtos comportamentais, espirituais e materiais da vida social humana.

Tylor relacionava a cultura a todas as manifestações humanas em sua dimensão coletiva, afastando a ideia de que a cultura seja fruto de hereditariedade biológica. Ou seja, para ele, a cultura encontra-se relacionada às realizações materiais dos homens.

Seguindo-se a Tylor, surge Franz, que realizou a crítica ao método comparativo da teoria evolucionista daquele etnólogo. "Tal metodologia detinha-se em encontrar semelhanças entre as diversas sociedades e compará-las com a sociedade europeia a fim de perceber em qual nível da escala civilizatória estaria o "outro" enquanto grupo" (SOILO, 2014, p. 254).

Os adeptos à teoria evolucionistas compreendiam "as sociedades não europeias como grupos inferiores na escala social, grupos que chegariam à evolução tal quais os europeus com o passar do tempo" (SOILO, 2014, p. 253). Para os evolucionistas esses grupos se encontravam em uma escala evolutiva que tendia a se tornar tal igual à sociedade europeia, que por ter evoluído, teria trilhado no passado os mesmos estágios culturais dos povos menos evoluídos.
Franz Boas criticava, além do evolucionismo, o racismo e, também, os determinismos geográfico, racial, psicológico (quando transposto dos indivíduos às culturas) e econômico, a partir dos quais foi definindo a importância do conceito de cultura como elemento explicativo da diversidade humana (CASTRO, 2005).

Apesar de sua formação inicial em Física e Matemática, foi a Geografia (física e humana) que levou Franz Boas à antropologia. Refere Cuche (2002) que Boas, foi o primeiro antropólogo a realizar pesquisas in situ na observação direta e prolongada das culturas primitivas.

Boas $(2010,113)$ define cultura como sendo o "conjunto das [...] reações e atividades mentais e físicas que caracterizam a conduta dos indivíduos que compõem um grupo social, coletiva e individualmente, em relação ao seu ambiente natural, a outros grupos, a membros do mesmo grupo e de cada indivíduo para consigo mesmo."

Pereira (2011) destaca que apesar dos pontos elencados por Boas serem indispensáveis para se entender o conceito de cultura, são insuficientes uma vez que seus elementos não são independentes, tendo em vista possuírem uma estrutura. Boas aponta que mesmo entre os animais é possível encontrar essa relação. Sendo assim, o peso do significado de cultura é atribuído à língua e outros elementos mais inerentes à atividade humana.

Mesmo inovando quanto à definição de cultura, que para ele deixa de ser uma única, Franz Boas abre um leque de diferentes interpretações para cultura e alerta a necessidade de uma análise cuidadosa para se entender este conceito "no âmbito da chamada cultura primitiva ou das classificadas como modernas" (PEREIRA, 2011, p. 108).

A partir dos estudos iniciais surgiram várias abordagens que buscaram explicar e 
problematizar a cultura nas diferentes áreas do conhecimento.

Partindo de uma linha, se não contínua, mas paralela a de Boas, Malinowski faz uma proposta de trabalho proveitosa para os que, além de compreender o processo cultural, pretendem atuar sobre ele. Para isso, Malinowski sugere que se deve entender uma cultura no presente, no seu presente, ao invés de remontar suas origens ou aquilo que se presume serem ou terem sido suas origens (COELHO, 2008).

Outro pensador de destaque é Clinfford Geertz, que trouxe nova dinâmica ao conceito de cultura ao acreditar, a exemplo de Max Weber, que o ser humano é um "animal amarrado a teias de significados que ele mesmo teceu, assumo a cultura como sendo essas teias e a sua análise; [...] não como uma ciência experimental em busca de leis, mas como uma ciência interpretativa, à procura do significado" (GEERTZ, 2008, p.4).

A esse respeito, Laraia (2009) complementa que para Geertz, os símbolos e significados são partilhados pelos membros do sistema cultural, portanto, estudar a cultura oportuniza analisar um código de símbolos partilhados pelos componentes dessa cultura.

Assim, a partir dessa visão, a cultura ocorre na mediação das relações dos seres humanos entre si, por meio da produção de sentidos e de seus significados.

Já o antropólogo Levi-Strauss "define cultura como um sistema simbólico que é uma criação acumulativa da mente humana. O seu trabalho tem sido o de descobrir na estruturação dos domínios culturais - mito, arte, parentesco e linguagem [...]" (LARAIA, 2009, p.61).

De acordo com Levi-Strauss a cultura foi criada no momento em que surgiu a primeira regra, que proibia o incesto, pelo motivo de que "A proibição do incesto está ao mesmo tempo no limiar da cultura, na cultura, e em certo sentido [...] é a própria cultura" (LÉVI-STRAUSS, 1982, p.50). Para este autor, a cultura nasce na convenção de normas e em sua formulação simbólica.

Cabe destacar, ainda Bourdieu, a quem Coelho (2008) elenca como sendo o teórico que raramente se serve do conceito antropológico de cultura, uma vez que sua preferência recai sobre a ideia restrita da cultura, simplificadamente, nos domínios das artes e das letras, que o motivou a investigar "os mecanismos sociais presentes na origem da criação artística e no processo de consumo da cultura nos diferentes grupos sociais" (COELHO, 2008, p.27).

Outros estudiosos também contribuíram para o conceito de cultura. Candau (2016) conceitua cultura como sendo práticas, representações, crenças, lembranças produzidas por uma sociedade. Já Pesavento (2005, p.15) refere que cultura é "uma forma de expressão e tradução da realidade que se faz de forma simbólica, $[\ldots]$ os sentidos conferidos às palavras, às coisas, às ações e aos atores sociais se apresentam de forma cifrada, portanto já um significado e uma apreciação valorativa". Chauí (1995), por sua vez, aponta a necessidade de se ampliar o conceito de cultura, adotando-o com o significado de invenção coletiva de símbolos, valores, ideias e comportamentos, visto que todos os indivíduos são sujeitos culturais.

Percebe-se a amplitude e a complexidade da ideia de cultura, uma vez que se relaciona com a produção de significados, ideias, valores, símbolos e comportamentos que constituem a formação cultural da vida e das práticas sociais das pessoas. Assim, as diversas formas de se perceber a sociedade, considerando a singularidade das diferentes culturas existentes, nos oportunizam pensar a importância da cultura, nos diferentes aspectos constitutivos de um povo. 


\section{A memória}

É desafiador discutir as diferentes dimensões da memória, suas relações com o patrimônio histórico cultural, com as ciências humanas e demais ciências, visto que os estudos sobre este tema, além de possibilitar entender fatos e tempos passados, possibilitam olhar para as representações simbólicas históricas, histórias de vida, registros materiais e imateriais que envolvem a cultura, a identidade, o pertencimento, a cidadania e uma gama de sentimentos e representações que fazem parte da vivência humana.

A memória tem sido objeto de estudo de diferentes áreas do conhecimento, que têm buscado entender e relacionar o seu funcionamento nos campos biológicos, psíquicos, psicológicos, neurofisiológicos, pedagógicos. Nesse universo, o estudo da memória social se insere em um campo amplo que se apoia, em certos momentos, em algumas dessas áreas disciplinares, usando dos seus conceitos.

Em sua obra Identidade Cultural na Pós-Modernidade, Stuart Hall (1998, p.56) faz uma interessante relação entre cultura nacional e construção da identidade, dizendo que o discurso da cultura nacional " [...] constrói identidades que são colocadas, de modo ambíguo, entre o passado e o futuro. Ele se equilibra entre a tentação por retornar a glórias passadas e o impulso por avançar ainda mais em direção da modernidade".

Apesar de a princípio a memória se apoiar na história vivida, experiências pessoais, como algo próprio do indivíduo, Halbwachs (1990) entende a memória do um fenômeno coletivo ou social construído coletivamente e sujeito a transformações constantes.

Pollak (1992, p. 204) entende a memória como sendo "é um elemento constituinte do sentimento de identidade, tanto individual como coletiva, na medida em que ela é também um fator extremamente importante do sentimento de continuidade e de coerência de uma pessoa ou de um grupo [...]".

As memórias são parte da nossa capacidade de olhar o mundo reunir sentimentos, emoções, sensações, experiências, que por algum motivo escolhemos guardá-las. Por isso as memórias necessitam de rememorações.

Refere Tedesco (2004), que memória, ao necessitar de imagens, dificulta o esquecimento, por parte de uma consciência simbólica, que nada mais é do um "sentir mais profundo da vida, do tempo e da identidade" (TEDESCO, 2004, p.49).

A memória é um importante suporte para se trabalhar história local, uma vez que demonstra aspectos familiares, das instituições, das comunidades e grupos de convívio. Possibilita, por meio das lembranças, trazer elementos de certo acontecimento do tempo histórico vivido para o presente (SOARES; MINUZZI; MACIEL, 2010).

Nós, seres humanos, precisamos de lugares de pertença, de significação, locais de memórias cristalizadas, onde as pessoas se reconheçam como grupo e se identifiquem individualmente ou coletivamente. Por isso os lugares de memória reforçam o sentimento de identidade e de pertença.

A temática memória nunca esteve tão em voga na atualidade e a valorização do patrimônio cultural corroborou para esta visibilidade. Chauí (2006) aponta os monumentos, documentos, coleções, objetos antigos e ícones, como edificações, cujo estilo desapareceu, bibliotecas, museus, dentre outros, como sendo suportes da memória.

As memórias fazem parte da capacidade da capacidade humana de reunir experiências, saberes, sentimentos, emoções que por algum motivo escolhemos guardar. Esses são essenciais à construção da identidade de um grupo uma vez que dão ideia de continuidade. Preservar a memória de um povo, ou de uma comunidade é um direito que se 
insere no contexto da cidadania cultural, ou seja, "a cultura como sendo um direito do cidadão" (CHAUÍ, 2006, p.69), um direito à sua memória histórica.

Tendo em vista cultura, identidade, pertencimento, memória, são atributos indispensáveis à Educação Patrimonial, esta por sua vez é uma questão de cidadania, o tema que será abordado a seguir.

\section{A cidadania}

A ideia de cidadania foi gradativamente construída, incorporando diferentes transformações ao longo da história da humanidade. Segundo Pinsky e Bossanezi (2013), a ideia de cidadania surgiu, inicialmente, entre o povo hebreu que, com sua ética religiosa e moral, oportunizaram o surgimento de ideias humanistas, principalmente através da ideia de um único Deus.

A cidadania em Atenas, na Grécia antiga, ligava-se a ideia de cidade-estado. Existiam várias normas que regulavam a obtenção da cidadania, em uma sociedade onde ser um cidadão era um direito estendido a poucos, o que acarretava um grande número de excluídos da cidadania, entre eles os estrangeiros, os escravos e as mulheres. Segundo Guarinello (2013, p.35) "pertencer à comunidade da cidade-estado não era, portanto, algo de pouca monta, mas um privilégio guardado com zelo, cuidadosamente vigiado por meio de registros escritos e conferido com rigor".

$\mathrm{Na}$ Roma antiga, a palavra cidadania foi utilizada como indicativo da situação política de uma pessoa e dos direitos que poderia ou não exercer. Na sociedade romana somente os romanos livres tinham o direito à cidadania. Contudo, neste universo, ainda havia distinção, "só os cidadãos ativos tinham direito de participar das atividades políticas e de ocupar os mais altos postos da administração pública. Uma particularidade deve ser ressaltada é que as mulheres não tinham a cidadania ativa [...]" (DALLARI, 2013, p.18).

Na Idade Média, a participação política era limitada a algumas circunstâncias vinculadas ao status social e econômico dos indivíduos. Nesse período os aspectos relativos à cidadania foram compostos por concepções filosóficas com base no cristianismo (BEDIN, 2008).

A concepção moderna de cidadania passou a ser construída a partir das revoluções burguesas, ocorridas entre os séculos XVII e XVIII (DALLARI, 2013), gestada a partir da efervescência de ideias oriundas das lutas sociais. De acordo com Odalia (2013) a Revolução Francesa foi culminância de um processo histórico de vinha se desenvolvendo. Este movimento revolucionário contribuiu para o fortalecimento do conceito de cidadania, uma vez que trouxe uma ruptura drástica na estrutura de poder na França, passando a definir os direitos individuais e coletivos dos homens como sendo universais.

Apesar de a Declaração dos Direitos do Homem e do Cidadão, publicada em 1789, tivesse ter a pretensão de um caráter universal a todos os cidadãos, indistintamente, novas desigualdades foram legalizadas, num claro sinal de discriminação pela cidadania.

No ano de 1791 os líderes da Revolução Francesa, reunidos numa Assembleia, aprovaram a primeira Constituição francesa e aí já estabeleceram regras que deformavam completamente a ideia de cidadania ativa. Recuperando a antiga diferenciação romana entre cidadania e cidadania ativa, [...] estabeleceram que para ter participação na vida política [...] era preciso ser cidadão ativo, não bastava ser cidadão. E dispuseram que para ter a cidadania ativa eram necessários certos requisitos [...] não bastava ser pessoa (DALLARI, 2013, p.20-21) 
Percebe-se que a cidadania idealizada na Revolução Francesa deixou de ser símbolo de igualdade ao privilegiar um grupo que considerou cidadãos ativos, ou seja, aqueles que diretamente permaneceriam no poder, com direito de votar e ser votado em Assembleia Nacional. Mais uma vez as mulheres e as camadas menos favorecidas da população foram excluídas do direito à cidadania ativa. Acredita Dallari (2013) que muitas vitórias foram conseguidas desde a Revolução Francesa, mas muito ainda falta caminhar para que a cidadania seja expressão de direito estendido a todos os setores da sociedade.

Fica mais claro o entendimento de cidadania se esta for entendida como a

[...] soma dos direitos civis, direitos políticos e direitos sociais conquistados, exatamente nessa ordem, pelos membros de uma sociedade, trata-se, então, de um conjunto de direitos e liberdades que exige reciprocidade de cada indivíduo, sendo, eminentemente, uma construção histórica (datada e geograficamente localizada) (CARDOSO JR., 2009, p.12).

No Brasil, a construção de direitos sociais não seguiu a mesma dinâmica dos países desenvolvidos. Explica Carvalho (2002 apud CARDOSO JR., 2009), que no Brasil, as fortes mudanças ocasionadas pela crise do café, no pós-1930, agravadas pela Revolução de 30 , truncaram os alicerces da cidadania brasileira moderna. Ou seja, Vargas governou a maior em parte do tempo em ditadura, concedendo direitos a partir de 1931, chegando seu auge durante a Segunda Guerra Mundial.

Nesse período foram criados direitos fundamentais ao trabalhador que existem ainda hoje, tais como férias, previdência, jornada de trabalho delimitada e salário mínimo, o que só virá a ser alterado com a entrada em vigor da nova legislação trabalhista.
Percebe-se que ao contrário da França, no Brasil, a construção da cidadania partiu dos direitos sociais e não dos direitos civis. Nosso processo de cidadania continuou sendo construído gradativamente e, ao mesmo tempo, a exemplo dos demais casos, também não houve um tratamento igualitário a todos os brasileiros. Outra consequência da criação dos direitos sociais foi, segundo Cardoso Jr. (2009, p.13), a garantia de direitos aos “[...] que tinham carteira de trabalho - configurou a construção de uma cidadania regulada, os direitos a serem concedidos eram os que o Estado julgava adequados, como também seus recebedores eram escolhidos entre a população urbana".

Com o Golpe Militar de 1964, a cidadania brasileira foi restringida no seu processo de construção, até o advento da Constituição Federal de 1988, denominada Constituição Cidadã, que em seu Artigo $1^{\circ}$, inciso $2^{\circ}$, apresenta a Cidadania como um dos seus fundamentos (BRASIL, 1988).

$\mathrm{Na}$ atualidade, a concepção de cidadania está atrelada à ideia de inclusão das populações excluídas, ou seja, indistintamente, todos e qualquer cidadão pertencente à sociedade deve tornar-se cidadão independente do seu status social, econômico, ideológico. A cidadania deve ser compreendida como uma possibilidade de inclusão de todos os segmentos da população (BERTASO, 2009).

Sabe-se que, na prática, uma parcela da população é excluída de um de seus mais elementares direitos de cidadania, a cultura, que na maioria das vezes é vista como desnecessária, em contrapartida às suas demandas mais básicas.

Diferentes elementos que compõem a cidade são representados por meio da memória, da identidade, por isso é muito importante entender o Direito à memória como sendo uma dimensão da cidadania implica reformular as relações entre nós e nossas produções en- 
quanto povo, assim como nossa participação ativa (MARTINS, 2015).

O termo cidadania está atrelado aos direitos e deveres de todas as pessoas que participam da sociedade civil. Todos os envolvidos devem ser atores conscientes dos processos decisórios e será a sua participação que determinará o exercício da sua cidadania. A cidadania é manifestada pelo compromisso do indivíduo com a sua sociedade e sua comunidade.

Por fim, é possível dizer que apesar de a Constituição Federal ter inovado ao incluir a cultura como um de seus fundamentos, bem como estender sua proteção ao patrimônio cultural material e imaterial, ainda há espaços sem o devido envolvimento de ações educativas, como estratégias de preservação do Patrimônio Cultural. O resultado não pode ser diferente, visto que esse tipo de fator é corresponsável:

[...] pela inexistência do sentimento de pertencimento dos habitantes por sua herança cultural. Por isso entendo que o caminho para a preservação e conservação do legado deixado a todos deve ser construído com os alicerces da educação patrimonial. Neste início de século intervenções de salvaguarda que não priorizem a educação patrimonial estão fadadas ao insucesso (SOUZA, 2013, p.51).

Reconhecer o patrimônio histórico e cultural é uma oportunidade para que a própria comunidade conte a sua história, fale de suas referências, de seus saberes, dos sentimentos coletivos e dos símbolos presente nessa representação. Por isso o patrimônio é uma representação da cultura, que está intrinsicamente ligada à cidadania, à identidade, ao sentimento de pertença. O descaso com relação a ele pode condenar as gerações futuras a perder esse referencial cultural e isso seria privá-las do seu direito à memória.

\section{Material e Métodos}

A proposta para a realização deste estudo foi por meio de uma pesquisa qualitativa, na modalidade de pesquisa-ação, com um grupo de crianças que participam de um programa que desenvolve atividades socioeducativas no município de Erechim.

O local do estudo é um espaço de educação não-formal, no município de Erechim-RS que desenvolve atividades com crianças e adolescentes, de ambos os sexos, pertencentes à rede pública de ensino. $\mathrm{O}$ estudo foi desenvolvido com crianças de idades que variam entre 9 e 14 anos, que estudam em uma escola pública da periferia de Erechim e que participam do referido programa. Por uma questão de logística, os professores do Programa dividem as crianças em dois grupos, o dos meninos e o das meninas. Tal divisão foi justificada em razão das atividades esportivas, nas quais os meninos, por terem mais habilidade física e força, e por serem fisicamente maiores, inviabilizam atividades conjuntas, buscando-se assim preservar as meninas.

Após dois encontros de observação, foram iniciados os encontros que culminaram em oficinas de educação patrimonial, organizadas para o grupo das meninas e após para o grupo dos meninos.

\section{Resultados e Discussão}

Para introdução do tema patrimônio histórico e educação patrimonial, inicialmente foi realizado um diálogo com as crianças as motivando a falar sobre Erechim, que completou 100 anos em 2018. Abordou-se então a ideia de patrimônio como fonte de história e memória, estimulando que falassem sobre objetos que são importantes para a família por 
trazerem a lembrança dos familiares (fotos, imagens, objetos dos avós, rezas, medalhinhas). Foi então falado sobre o quanto este patrimônio é insubstituível e o valor que se atribui a eles.

A partir da ideia de patrimônio familiar foi falado do patrimônio deixado por povos que viveram antes de nós e que fazem parte da história de Erechim e região, sendo que através da arqueologia foi possível resgatar seus vestígios e contar como viviam, a sua alimentação, seus abrigos, suas cerimônias de vida e de morte.

A seguir foi perguntado às crianças se sabiam que, antes da chegada dos imigrantes e seus descendentes à Região Alto Uruguai, índios e caboclos habitavam essas terras. Segundo Schmitz (2009), registros arqueológicos apontam que há aproximadamente 6 mil anos a.C grupos humanos já habitavam as encontras dos rios e as florestas da região, o que pode ser evidenciado nos vestígios arqueológicos que comprovam acampamentos profundamente enterrados nos barrancos do Alto Uruguai.

Com o auxílio de apresentação em PowerPoint e de um cartaz que mostrava fases de uma ocupação humana, abandono do local e formação de registros líticos (pontas de flechas, raspadores, facas, mão de pilão, machadinhas construídas a partir de rochas da região e vasilhas em cerâmica) que se acomodaram em várias camadas do solo ao longo do tempo, foi explicada a dinâmica da vida dos grupos indígenas, a alimentação, a produção de ferramentas a partir do lascamento e polimento de pedras.

Seus acampamentos eram temporários e a abundância de água, os recursos de caça e de coleta eram o que atraía esses homens e tornavam sua vida possível. Os instrumentos abandonados nesses acampamentos eram compostos principalmente de grandes enxós, raspadores, talhadores e cunhas lascadas que seriam usados para abrir clareiras na floresta e trabalhar a madeira. A matéria-prima utilizada para confeccionar esses instrumentos costumava ser o basalto, o diabásio, o riolito ou o arenito silicificado, que havia em abundância junto às corredeiras dos rios sob a forma de seixos ou nas encostas onde surgiam em grandes blocos. Raramente aparece a calcedônia e o quartzo que eram usados para criar pequenos artefatos (SCHMITZ, 2009).

$\mathrm{Na}$ sequência, foram apresentadas imagens da localização dos sítios arqueológicos na região Alto Uruguai onde foram encontrados materiais líticos, lascamentos e cerâmicas. Mostrou-se, também os locais onde foram descobertas casas subterrâneas, na região de planalto do RS. Conforme estudos realizados por Schmitz (2009), as evidências sugerem que esses grupamentos eram formados por um ou vários núcleos familiares que viviam próximos e se alimentavam da coleta de frutos, caça e pesca.

De acordo com Chiaparini (2012, p.12), "os Kaingang "kaa = mato + ingáng = morador $=$ habitante do mato [...] habitavam as áreas do Planalto-Médio e Norte rio-grandense" e, conforme complementa Becker (2006, p.125), “Os Kaingang [...], prováveis moradores das casas subterrâneas do Planalto [...] eram índios coletores, especialmente de pinhão, caçadores, pescadores e pequenos horticultores".

O material lítico encontrado nos sítios arqueológicos do Rio Grande do Sul é apresentado por Schmitz (2016, p.13) como sendo "muito simples, predominantemente lascado, feito de peças grandes, em rocha local". Quanto às cerâmicas resgatadas nos sítios arqueológicos gaúchos, Schmitz (2016, p.13) verificou que "Entre os artefatos que se conservaram, destaca-se o vasilhame cerâmico, pequeno e altamente decorado por impressões plásticas [...]".

Após a apresentação das imagens de materiais líticos encontrados em sítios ar- 
queológicos da Região Alto Uruguai, foram distribuídos blocos de argila ao grupo dos meninos, que passou a explorar esse material e a moldar casas subterrâneas, ferramentas e materiais representando os instrumentos utilizados pelos indígenas em seu cotidiano para cortar, moer ou raspar, e ainda as pontas de flecha e de lanças, usadas nas atividades de caça. Em seguida as peças moldadas foram colocadas para secar.

No encontro seguinte foi desenvolvido o conteúdo de forma semelhante com as meninas, só que ao invés de material lítico, foram apresentadas ilustrações das diferentes cerâmicas produzidas pelos povos indígenas do Rio Grande do Sul. Foram explicadas as técnicas para a construção das cerâmicas, os tipos de decoração, sua utilização como recipiente para líquidos e alimentos, ou como urna funerária, etc. Neste dia simulamos uma atividade de laboratório de arqueologia, onde cada grupo de 4 integrantes recebeu cerâmicas quebradas, as quais precisaram montar e colar. As meninas se surpreenderam com a quantidade de cacos de tamanhos variados, dos quais exploraram a espessura, formato, $\mathrm{e}$ acharam interessante que iguais às cerâmicas kaingang, das imagens projetadas, alguns potes não possuíam todas as partes, que se esmigalharam durante a quebra da peça que seria utilizada na oficina.

Concluída a construção da cerâmica, iniciou-se uma segunda atividade, para a qual foram disponibilizados blocos de argila sobre as mesas para oportunizar que cada menina construísse a sua cerâmica, podendo escolher a técnica de construção e decoração (roletada com acabamento simples ou ungulada), para posterior pintura da peça. As alunas não esperavam pela atividade com a argila, uma vez que já haviam realizado a colagem dos potes em cerâmica, o que foi muito motivador, pois semelhante aos meninos, a maioria nunca havia trabalhado com argila. Todas se empenharam muito, foram extremamente criativas, o que resultou na construção de lindos potes que, após a secagem, no encontro seguinte, foram pintados com tinta guache.

Ao término de cada oficina as crianças foram motivadas a falar sobre o que aprenderam e qual o significado e importância atribuídos ao patrimônio, de que forma ele registra a história, qual foi a sua função e como resistiu ao tempo. Neste momento foi falado do patrimônio material e imaterial, realizando-se uma análise crítica dos mesmos e procurando relacioná-lo com a atualidade.

Dias e Soares (2008, p.54) acreditam que "não é possível esperar que a população de qualquer município, valorize aquilo com que não se identifica, imposto como patrimônio [...]", por isso a importância de se conhecer o passado para ver nas diferentes experiências humanas ocorridas, uma oportunidade para se pensar sobre elas, para que dessa forma se possa interpretá-las e relacioná-las com o tempo presente.

Além de atrativas, as atividades arqueológicas em forma de oficina, por serem lúdicas, oportunizam que a criança faça relações do objeto com o contexto em que foi usado, ficando mais fácil entender o patrimônio histórico/cultural evidenciado.

Dentre as diferentes interpretações levantadas pelas crianças durante a construção e reconstrução dos objetos, percebeu-se que eram variados pontos de vistas que buscavam explicar o passado dos grupos humanos que viveram na região do Alto Uruguai antes da colonização. Foram criadas hipóteses sobre a vida desses povos e do motivo do abandono dos locais em que viviam, assim como de seus artefatos

Foi perceptível a surpresa de que os indígenas que costumeiramente transitam pela cidade vendendo artesanato são remanescentes dos povos que construíram as peças líticas e cerâmicas encontradas nos sítios arqueológi$\cos$ da região, o que foi muito oportuno para 
se abordar a cultura kaingang, a imposição do aldeamento, enfim, a entenderem de que a imagem criada do indígena não condiz com a realidade.

Soares, Perius e Arent (2013) ao analisarem livros didáticos de História, perceberam a inadequação de como pré-história e os povos indígenas têm sido retratados, o que tem demonstrado a falta de conhecimento sobre a arqueologia. Os autores destacam a importância da arqueologia referindo que:

A arqueologia vem desempenhando um papel significativo no processo de ensino por representar uma prática de pesquisa, atuando na produção do conhecimento com foco em todas as etapas de desenvolvimento da humanidade, considerando todas as espécies e culturas que se desenvolveram ao longo do processo histórico. Ela ressalta a importância de cada espécie na formação dos grupos e sociedades atuais, tendo em seu objeto de estudo, os vestígios materiais deixados pelos humanos que na Terra um dia habitaram. Torna-se, portanto, um método de ensino não excludente e que reforça a reavaliação e reelaboração dos conteúdos de livros didáticos utilizados no ensino em nosso país (SOARES; PERIUS; ARENT, 2013, p. 528)

A arqueologia indaga os vestígios deixados pelos homens ou sociedades passadas, contudo, se essas indagações não servirem ao homem do presente na compreensão de sua condição de ser social, de agente transformador, de nada isso adiantará (CAMPOS et al., 2016). Por isso, não basta apenas recuperar os vestígios materiais dos que viveram antes de nós e lutar pela sua preservação, mas imprescindível que se conscientize a sociedade a respeito da importância de se valorizar esses saberes e tradições e, acima de tudo, respeitar os seus bens culturais.

\section{Conclusão}

As oficinas de Educação Patrimonial desenvolvidas com estudantes de uma escola de periferia que participam de um programa que proporciona atividades socioeducativas, no município de Erechim oportunizaram refletir sobre a região onde se constituiu o Erechim; caboclos e indígenas - povos que aqui viviam antes da chegada dos colonizadores; os caçadores e coletores que habitaram o estado, conforme comprovam os artefatos líticos, cerâmicas, casas subterrâneas, enfim, registros arqueológicos de sua cultura, relações sociais (de vida e morte), a forma como usavam o espaço.

As atividades, desenvolvidas de forma lúdica e prazerosa, oportunizaram uma discussão rica que abordou, por meio da arqueologia e da educação patrimonial, uma parte da história pregressa de povos que habitavam a região antes da chegada dos colonizadores. Povos que foram impactados pela colonização e que, muitas vezes, não são reconhecidos pela sua importância histórica e cultural.

A proposta de Educação Patrimonial utilizadas nas oficinas se efetivaram em forma de inclusão social, pois trabalhar com os objetos culturais indígenas, que historicamente não são reconhecidos e têm sido colocados à margem da sociedade, é uma forma de ensinar às crianças sobre a importância de se valorizar e da preservar os saberes e tradições desses povos e, principalmente, demonstrar-lhes o respeito à diferença, seja ela étnica, cultural ou religiosa, entendimento que possibilita aos indivíduos verem-se como cidadão e a defenderem seus direitos.

Além disso, as crianças entenderam que todas as atividades e práticas sociais são manifestações da cultura, que existem diferentes culturas e que todos, de alguma forma, somos influenciados pela cultura. Ficaram bastante 
impactados quando abordamos a questão do respeito à diversidade cultural, relacionada à questão da cultura indígena. Nesse momento algumas crianças falaram de sua descendência indígena, e percebo um certo orgulho em contar esta novidade. Neste momento, fizeram referência a histórias contadas pelos avós sobre os antepassados, de como viviam e de onde vieram. Foi quando foi abordada a importância da memória para reforçar o sentimento de pertença e a identidade, o que é direito de todo o cidadão.

O ano de 2018 foi repleto de comemorações dos 100 anos da criação da Colônia Erechim, que foi Paiol Grande; Boa Vista; Boa Vista do Erechim; que também se chamou José Bonifácio, para só em 1944 receber o nome de Erechim, em referência à antiga Colônia. A cidade se cresceu, contudo, o desenvolvimento não pode ser aceito com a destruição da história, com a falta de memória ou com o aniquilamento da cultura. Por isso, agora passados mais de "100 anos" da cidade de Erechim, é de grande relevância a abordagem de temas que oportunizem o reconhecimento e o respeito à diversidade cultural e étnica das diferentes populações, pois o patrimônio cultural reflete a pluralidade e a diversidade das culturas dos povos que o formaram, sua trajetória, seus modos de vida, seus valores e características que os diferenciam de outras populações, por isso a sua riqueza em significados.

\section{REFERÊNCIAS}

BECKER, Í.I.B. O que sobrou dos índios pré-históricos do Rio Grande do Sul. In: SCHMITZ, Pedro Ignácio. PRÉ-HISTÓRIA do Rio Grande do Sul: Arqueologia do Rio Grande Do Sul, Brasil.

BEDIN, G.A. A Idade Média e o nascimento do Estado Moderno: Aspectos Históricos e Teóricos. Ijuí: UNIJUI, 2008.

BERTASO, J.M. (Org.). Cidadania, diversidade e reconhecimento: produção associada ao projeto de pesquisa 'Cidadania em sociedades multiculturais: incluindo o reconhecimento'. Santo Ângelo: FURI, 2009.

BOAS, F. A mente do ser humano primitivo. Petrópolis, RJ: Vozes, 2010.

BOURDIEU, P. O senso prático. 2 ed. Petrópolis, RJ: Vozes, 2011.

BRASIL. Constituição (1988). Constituição Federal. São Paulo: Revista dos Tribunais, 2008.

BRASIL. Decreto Lei $\mathbf{n}^{\circ} \mathbf{2 5}$, de 30 de novembro de 1937. Organiza a proteção do patrimônio histórico e artístico nacional. Disponível em: http://www.planalto.gov.br/ ccivil/Decreto-Lei/ Del0025.htm. Acesso em: 15 maio 2018.

CAMPOS, J.B. et al. Patrimônio e cidadania: a educação patrimonial nas escolas e a formação cidadã. Revista Memorare, v. 3, n. 1, p. 95-113, 2016.

CANDAU, J. Memória e Identidade. São Paulo: Contexto, 2016.

CARDOSO JÚNIOR, J.C. A Constituição brasileira de 1988 revisitada: recuperação histórica e desafios atuais das políticas públicas nas áreas econômica e social. Brasília: Ipea, 2009.

CASTRO, C. Apresentação. In: BOAS, F. Antropologia cultural. 2.ed. Rio de Janeiro: Jorge Zahar, 2005.

COELHO, T. A cultura e seu contrário: cultura, arte e política pós-2001. São Paulo: Iluminuras: Itaú Cultural: 2008 
CHAUÍ, M. Cidadania cultural: o direito à cultura. São Paulo: Fundação Perseu Abramo, 2006. CHAUÍ, M. Cultura política e política cultural. Estudos Avançados, v.9, n.23, p.71-84, 1995.

CHIAPARINI. E.J. Erechim: Retratos do passado, memórias do presente. Erechim: Graffoluz, 2012.

CUCHE, D. O Conceito de Cultura nas Ciências Sociais. Bauru: EDUSC, 2002.

DALLARI, D.A. Direitos humanos e cidadania. 2. ed. São Paulo: Moderna, 2013.

DIAS, G.; SOARES, A.L.R. Educação Patrimonial e educação popular: um viés possível. In: SOARES, A.L.R.; KLAMT, S.C. (Org.). Educação Patrimonial: Teoria e Prática. Santa Maria: UFSM, 2008.

GEERTZ, C. A interpretação das culturas. 1. ed., Reimpr. Rio de Janeiro: LTC, 2008.

GUARINELLO, N.L. Cidades-Estado na antiguidade clássica. In: PINSKY, J.; BOSSANEZI, C. (Orgs.). A História da Cidadania. 6. ed. São Paulo: Contexto, 2013.

HALBWACHS, M. A memória Coletiva. São Paulo: Revista dos Tribunais, 1990.

HALL, S. A identidade cultural na pós-modernidade. Rio de Janeiro: DP\&A, 1998.

HOUAISS, A. Dicionário Houaiss da língua portuguesa. Rio de Janeiro: Objetiva, 2009.

IPHAN. Educação Patrimonial: Histórico, conceitos e processos. Brasília-DF: Iphan/DAF/ Cogedip/Ceduc, 2014.

LARAIA, R.B. Cultura: um conceito antropológico. 24 ed. Rio de Janeiro: Jorge Zaak, 2009.

LEMOS, C.A.C. O que é patrimônio histórico. 2. ed. São Paulo: Brasiliense, 2013.

LE GOFF, J. História e memória. 5. ed. Campinas, SP: Unicamp, 2010.

LÉVI-STRAUSS, C. As Estruturas elementares do parentesco. Petrópolis, Vozes, 1982.

MARCONI, M.A.; PRESOTTO, Z.M.N. Antropologia: uma introdução.5. ed. São Paulo: Atlas, 2001. MARTINS, J.C.O. Patrimônio cultural: sujeito, memória e sentido para o lugar. In. PINHEIRO, A.R.S. (Org.). Cadernos do patrimônio cultural: educação patrimonial. Fortaleza: Secultfor: Iphan, 2015.

ODALIA, N. A Liberdade como meta coletiva. In: PINSKY, J.; BOSSANEZI, C. (Orgs.). A História da Cidadania. 6. ed. São Paulo: Contexto, 2013.

OLIVEIRA, E.; ALVES, A.F. Uma Análise Literária sobre o Conceito de Cultura. Revista Brasileira de Educação e Cultura, n.10, p.1-18, jan.-jun., 2015.

PEREIRA, J.C. Educação e cultura no pensamento de Franz Boas. Ponto-e-Vírgula (PUCSP), São Paulo, p. 01-118, 10 set. 2011.

PESAVENTO, S.J. História \& história cultural. 2. ed. Belo Horizonte: Autêntica, 2005.

PINSKY, J.; BOSSANEZI, C. (Orgs.). A História da Cidadania. São Paulo: Contexto, 2013.

POLLAK, M. Memória e identidade social. Estudos Históricos, Rio de Janeiro, v.5, n.10, p. 200212, 1992.

RAMOS, A.C.P.T. A preservação de bens culturais no Brasil - respeito e conscientização social.

Revista Noctua, v.1, p.79-96, 2016.

RIBEIRO, D. O povo brasileiro: a formação e o sentido do Brasil. 2. ed. São Paulo: CIA das Letras, 2004.

SCHMITZ, P.I. Arqueologia do Rio Grande do Sul, Brasil. São Leopoldo: Instituto Anchietano de Pesquisas, 2009. 
SCHMITZ, P.I. A Arqueologia do Jê Meridional: uma longa aventura intelectual. Cadernos do CEOM - Estudos arqueológicos regionais, v.29, n.45, p.7-32, 2016.

SOARES, A.L.R.; MINUZZI, J.D.O.; MACIEL, R.B. Memória e história local como patrimônio. Mouseion, n.10, p.130-134, 2011.

SOARES, A.L.R.; PERIUS, E.; AREND, J.F. A arqueologia nos livros didáticos. Revista LatinoAmericana de História, v.2, n.6, p.520-531, 2013.

SOILO, A.N. Do evolucionismo clássico ao particularismo histórico na antropologia: principais ideias. Tessituras, v. 2, n. 1, p. 251-261, 2014.

SOUZA, I.A.N. Educação Patrimonial nos documentos patrimoniais: Constituição de 1988 e planos de salvaguarda. TOLANTINO, Á.B. (Org.) Educação patrimonial: educação, memórias e identidades. João Pessoa: Iphan, 2013. (Caderno Temático, 3)

TEDESCO, J.C. Nas cercanias da memória: temporalidade, experiência e narração. Passo Fundo: Ediupf, 2004. 